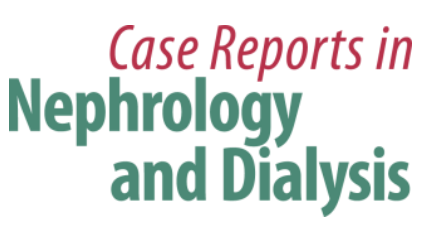

Case Rep Nephrol Dial 2016;6:32-39

\title{
Acute Respiratory Distress Syndrome and Posterior Reversible Encephalopathy Syndrome following Rituximab Therapy
}

\author{
Katrina E. Wardrope ${ }^{\mathrm{a}}$ Lynn Manson ${ }^{\mathrm{b}}$ Wendy Metcalfe ${ }^{\mathrm{a}}$ \\ Eoin D. O Sullivan ${ }^{\mathrm{a}}$ \\ ${ }^{a}$ Department of Renal Medicine, Royal Infirmary of Edinburgh, and ${ }^{\mathrm{b}} \mathrm{Scottish}$ National \\ Blood Transfusion Service, Edinburgh, UK
}

\section{Key Words}

Rituximab - Acute respiratory distress syndrome $\cdot$ Posterior reversible encephalopathy syndrome $\cdot$ Cryoglobulinaemia

\begin{abstract}
The anti-CD20 monoclonal antibody rituximab is associated with rare but significant adverse events, notably posterior reversible encephalopathy syndrome (PRES) and acute respiratory distress syndrome (ARDS). We report a case of concomitant ARDS and PRES developing after rituximab therapy for treatment of cryoglobulinaemic vasculitis. There are 7 reported cases of PRES complicating rituximab use. PRES onset varied from immediate to 21 days after administration. All patients recovered completely, and rituximab was reintroduced in half of the cases. The occurrence of ARDS in association with rituximab is rarer. Only 3 confirmed cases exist, and ARDS may occur as a delayed reaction.

(C) 2016 The Author(s)

Published by S. Karger AG, Basel
\end{abstract}

\section{Background}

The anti-CD20 monoclonal antibody rituximab is increasingly used in the treatment of haematological malignancies such as non-Hodgkin's lymphoma and chronic lymphocytic leukaemia, rheumatoid arthritis and ANCA-associated vasculitis. Adverse effects range from the common (infusion reactions, pancytopenia, bacterial and viral infections and cardiac

\section{KARGER}

Dr. Eoin D. O Sullivan

Department of Renal Medicine, Royal Infirmary of Edinburgh

51 Little France Crescent

Edinburgh EH16 5SY (UK)

E-Mail eoindosullivan@gmail.com 


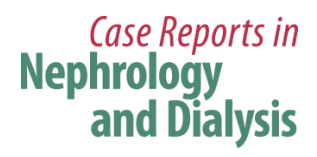

Case Rep Nephrol Dial 2016;6:32-39

DOI: $10.1159 / 000444250$

(c) 2016 The Author(s). Published by S. Karger AG, Basel www.karger.com/cnd

Wardrope et al.: Acute Respiratory Distress Syndrome and Posterior Reversible Encephalopathy Syndrome following Rituximab Therapy

events) to the rare (progressive multifocal leukoencephalopathy, cytokine release syndrome and respiratory failure).

Here we present the development of acute respiratory distress syndrome (ARDS) and posterior reversible encephalopathy syndrome (PRES) in a patient undergoing rituximab treatment for cryoglobulinaemia of uncertain aetiology.

\section{Case Report}

A 60-year-old female was admitted from a renal outpatient clinic for investigation of acute kidney injury and a diffuse constellation of symptoms. She had intermittent haematuria for 1 week prior to her visit, small and large joint aches, increasing peripheral oedema, two discreet episodes of epistaxis and had noticed a purpuric rash spreading over her lower shins and heels bilaterally for the prior 3 days. Her blood pressure in clinic was 149/99. Her urinalysis was 3+ positive for protein and her urinary protein:creatinine ratio was found to be 516. Past medical history was notable only for culture-negative cutaneous tuberculosis treated in 2013. The patient's initial blood tests on arrival and subsequent vasculitic screen are summarised in table 1.

An echocardiogram was normal, suggesting there was no coexistent heart failure. A renal biopsy demonstrated mesangiocapillary glomerulonephritis with multifocal extraglomerular necrotising vasculitis. Immunofluorescence demonstrated large amounts of IgM and IgG in a granular distribution along capillary walls. Electron microscopy demonstrated endocapillary hypercellularity with scattered subendothelial irregular electron-dense deposits and dark electron-dense areas with fine granularity rather than an ordered clear structure. This was in keeping with immunocomplex membranoproliferative glomerulonephritis secondary to cryoglobulinaemia.

This patient's cryoglobulins precipitated out of serum over $6 \mathrm{~h}$, and immunofixation suggested type 1 due to a monoclonal IgMk paraprotein. Low levels of C4 were detected, and there was no rheumatoid factor detected in the cryocrit.

A bone marrow aspirate and trephine was performed to exclude underlying myeloproliferative disease, which demonstrated only reactive marrow. A CT TAP was performed to investigate for underlying malignancy which could be driving the cryoglobulinaemia. This demonstrated a small area of small bowel thickening in the duodenum, and small pleural effusions. This region of bowel was biopsied endoscopically; however, no luminal abnormality could be seen. The biopsy returned as normal.

A bronchoscopy was performed to exclude any active tuberculosis due to her history and abnormal CT thorax findings. This showed unremarkable lavage. There were no acid fast bacilli on Ziehl-Neelsen staining.

Our patient's renal function and oedema continued to worsen. On admission, she was commenced on frusemide $80 \mathrm{mg}$ i.v. b.d., but due to her worsening oedema and newly developing oliguria, a decision was made to commence regular ultrafiltration. In light of her progressive renal dysfunction, and now worsening vasculitic rash, she was commenced on triple immunosuppression with alternative day plasma exchange (with IVIG $5 \mathrm{~g}$ ), prednisolone $(1 \mathrm{mg} / \mathrm{kg} /$ day) and rituximab (375 mg/m² in weekly doses; $600 \mathrm{mg}$ given).

Therapy for type 1 cryoglobulinaemia is unclear, but it has been suggested this should have similarities to that which one would apply to a B-cell disorder, given this is most often the underlying cause [1]. There are small case series suggesting rituximab is safe in mixed cryoglobulinaemia alone or in combination, and at least one trial has suggested it has superior efficacy to cyclophosphamide in a mixed cryoglobulinaemic population including cryo- 


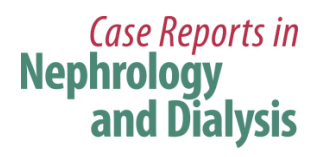

Case Rep Nephrol Dial 2016;6:32-39

Wardrope et al.: Acute Respiratory Distress Syndrome and Posterior Reversible Encephalopathy Syndrome following Rituximab Therapy

globulinaemic vasculitis [2, 3]. What little evidence does exist for type 1 cryoglobulinaemia suggests rituximab is safe and effective [4]. This is supported by longer-term registry data suggesting rituximab is both effective and well tolerated [5].

The trial data from ANCA-associated vasculitis suggest cyclophosphamide and rituximab have similar side effect profiles $[6,7]$. We felt that we would not be putting our patient unduly at risk by choosing rituximab under the circumstances.

Two days after the initial dose of rituximab, she developed acute respiratory distress and was found to be in florid pulmonary oedema (fig. 1). This was managed successfully by ultrafiltration. She received a second dose of rituximab 1 week later, and within $24 \mathrm{~h}$ developed tonic-clonic seizures, severe hypertension (averaging 170/100) and a further episode of flash pulmonary oedema necessitating intubation and ventilation.

On extubation, she was encephalopathic and hyperreflexic. MRI of the head revealed subcortical white matter high T2 and FLAIR signal in the occipital and posterior parietal lobes consistent with PRES (fig. 2). She was loaded with phenytoin (500 mg i.v.), and blood pressure was noted to be $200 / 100$. This was controlled with increasing her oral antihypertensive agents. Repeat bronchoscopy and BAL demonstrated active neutrophils, consistent with ARDS, but no evidence of infection.

She did not receive any further rituximab but continued with plasma exchange, i.v. immunoglobulin and prednisolone. Her repeat cryoglobulin levels decreased but remained detectable despite alternate day plasma exchange for 2 weeks, prompting the initiation of cyclophosphamide (500 mg i.v.).

There have been no further seizures, and her encephalopathy completely resolved over the course of 10 days. Following 1 dose of cyclophosphamide, the cryoglobulin titre fell to undetectable levels. All immunosuppression and plasma exchange were thus discontinued; the cryoglobulin remains undetectable at 8 months of follow-up. Her creatinine has stabilised at $160 \mu \mathrm{mol} / \mathrm{l}$ giving our patient an estimated GFR of $30 \mathrm{ml} / \mathrm{min} / 1.73 \mathrm{~m}^{2}$ and a protein:creatinine ratio of 219 .

\section{Discussion}

PRES is a radiopathological description of neurotoxic state coupled with distinctive radiological findings $[8,9]$. While the classical description is of predominantly posterior white matter patchy changes, there is an increasing recognition of a variety of findings such as temporal lobe or thalamic involvement, haemorrhage and unilateral findings [10]. Symptoms can be diverse, ranging from minor perturbations in conscious level through to seizures, encephalopathy and coma.

The aetiology is incompletely understood, but proposed theories suggest a key step is the loss of cerebral autoregulation resulting either in local hypertension and breakthrough haemorrhage, or abnormal reflex vasoconstriction and subsequent local ischaemia and vasogenic oedema [11-13]. PRES has been associated with a number of disease states such as eclampsia, malignant hypertension, systemic lupus erythematosus and malignancy as well as a potential association with a number of drugs, particularly calcineurin inhibitors, cyclophosphamide and a variety of monoclonal agents [14-16]. Similar to the majority of reports of drug-associated PRES, our case had a number of coexisting risk factors, suggesting a high cumulative risk being an important component in the development of PRES.

A review of the literature revealed six other cases attributing the occurrence of PRES to rituximab, the characteristics of which are summarised in table 2. Underlying disease associations varied, from B-cell lymphoma (50\%) to systemic lupus erythematosus, hepatitis C and 


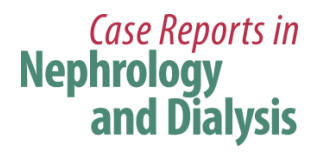

Wardrope et al:: Acute Respiratory Distress Syndrome and Posterior Reversible Encephalopathy Syndrome following Rituximab Therapy

neuromyelitis optica [17-20]. To the best of our knowledge, there are no cases of type 1 cryoglobulinaemia leading to PRES; thus, whether or not it is an established risk factor for development of PRES is debatable.

The onset of symptoms of PRES ranges from an immediate intra-infusion reaction to a delayed reaction 3 weeks after the first dose. While some cases reported reoccurrence of a neurological deficit after repeated doses of rituximab, this was an unpredictable response and often occurred after uneventful previous infusions. All cases had full clinical resolution on withdrawal of rituximab and supportive care. It took between $24 \mathrm{~h}$ and 2 weeks for full symptom resolution. Interestingly, 3 cases resumed therapy. Of note, our patient had a number of potential risk factors in the form of her acute kidney injury, fluid overload, hypertension, cryoglobulinaemia and rituximab.

\section{Rituximab and ARDS}

In contrast to PRES, there is a stronger and well-documented association between rituximab usage and noninfectious pulmonary complications [21]. There is a broad range of respiratory syndromes associated with rituximab. While the commonest presentation is interstitial pneumonitis, diverse pathology including bronchiolitis obliterans organising pneumonia, usual interstitial pneumonia and hypersensitivity pneumonitis can occur. In the largest review to date, of 121 cases of rituximab-associated lung injury, there are 3 cases of ARDS, presenting as in our case with acute respiratory failure and diffuse bilateral infiltrates on chest X-ray and CT imaging [21]. The onset is unpredictable, and can vary from hyperacute pulmonary oedema during a first infusion to a delayed reaction triggered by a third infusion weeks after initiation of therapy $[22,23]$.

Rituximab exerts its therapeutic effect against CD20-positive cells by inducing apoptosis and cell-mediated cytotoxicity and by activating the complement cascade [24]. Patients treated with rituximab have detectably higher levels of tumour necrosis factor-alpha and complement C3a [25]. This pro-inflammatory milieu may well be the driving factor behind the sudden increase in pulmonary alveolar permeability and inflammation leading to ARDS. Despite the high morbidity and mortality of these side effects, when they do occur, rituximab has revolutionised therapy for many diseases and indeed can be used to treat both PRES and ARDS even in many of the same disease states that we have described in the summary table [25-28]. It is important for clinicians to be aware of the potential side effects of rituximab and consider the difficulties in balancing the unwanted effects of therapy with the necessity to control underlying disease processes.

Serious adverse reactions to rituximab remain rare, and when they do occur, it is often in patients which several multiplicative risks. A pragmatic approach may be to minimise known risk factors such as hypertension, proteinuria or concomitant calcineurin inhibitor usage if feasible before commencing rituximab therapy.

Our experience suggests that PRES and ARDS are rare, unpredictable and idiosyncratic reactions to rituximab, and rituximab remains a logical choice as an anti-B-cell immunosuppressive agent in a case such as this. While our patient recovered, overall mortality in patients who develop ARDS remains high. 
Wardrope et al:: Acute Respiratory Distress Syndrome and Posterior Reversible Encephalopathy Syndrome following Rituximab Therapy

\section{Learning Points}

1 PRES and ARDS as adverse reaction to rituximab remain rare but are increasingly recognised.

2 When PRES occurs following rituximab treatment, it is often in patients which several coexisting risk factors.

3 Our experiences to date suggest that PRES will resolve over a number of days with supportive care.

\section{Statement of Ethics}

Written consent was obtained from our patient, giving permission for her case notes and images to be used in this publication.

\section{Disclosure Statement}

The results presented in this paper have not been published previously in whole or part, except in abstract form. We have no conflicts of interest to report. No funding was received for this work.

\section{References}

1 Cacoub P, Comarmond C, Domont F, Savey L, Saadoun D: Cryoglobulinemia vasculitis. Am J Med 2015;128:950-955.

-2 Ferri C, Cacoub P, Mazzaro C, Roccatello D, Scaini P, Sebastiani M, Tavoni A, Zignego AL, De Vita S: Treatment with rituximab in patients with mixed cryoglobulinemia syndrome: results of multicenter cohort study and review of the literature. Autoimmun Rev 2011;11:48-55.

-3 De Vita S, Quartuccio L, Isola M, Mazzaro C, Scaini P, Lenzi M, Campanini M, Naclerio C, Tavoni A, Pietrogrande M, Ferri C, Mascia MT, Masolini P, Zabotti A, Maset M, Roccatello D, Zignego AL, Pioltelli P, Gabrielli A, Filippini D, Perrella O, Migliaresi S, Galli M, Bombardieri S, Monti G: A randomized controlled trial of rituximab for the treatment of severe cryoglobulinemic vasculitis. Arthritis Rheum 2012;64:843853.

4 Wink F, Houtman PM, Jansen TLTA: Rituximab in cryoglobulinaemic vasculitis, evidence for its effectivity: a case report and review of literature. Clin Rheumatol 2011;30:293-300.

5 Terrier B, Launay D, Kaplanski G, Hot A, Larroche C, Cathébras P, Combe B, de Jaureguiberry JP, Meyer O, Schaeverbeke T, Somogyi A, Tricot L, Zénone T, Ravaud P, Gottenberg JE, Mariette X, Cacoub P: Safety and efficacy of rituximab in nonviral cryoglobulinemia vasculitis: data from the French Autoimmunity and Rituximab registry. Arthritis Care Res (Hoboken) 2010;62:1787-1795.

6 Jones RB, Tervaert JWC, Hauser T, Luqmani R, Morgan MD, Peh CA, Savage CO, Segelmark M, Tesar V, van Paassen P, Walsh D, Walsh M, Westman K, Jayne DRW: Rituximab versus cyclophosphamide in ANCAassociated renal vasculitis. N Engl J Med 2010;363:211-220.

7 Stone JH, Merkel PA, Spiera R, Seo P, Langford CA, Hoffman GS, Kallenberg CGM, St Clair EW, Turkiewicz A, Tchao NK, Webber L, Ding L, Sejismundo LP, Mieras K, Weitzenkamp D, Ikle D, Seyfert-Margolis V, Mueller M, Brunetta P, Allen NB, Fervenza FC, Geetha D, Keogh KA, Kissin EY, Monach PA, Peikert T, Stegeman C, Ytterberg SR, Specks U: Rituximab versus cyclophosphamide for ANCA-associated vasculitis. N Engl J Med 2010;363:221-232.

-8 Bartynski WS: Posterior reversible encephalopathy syndrome, part 1: fundamental imaging and clinical features. AJNR Am J Neuroradiol 2008;29:1036-1042.

-9 Stevens CJ, Heran MKS: The many faces of posterior reversible encephalopathy syndrome. Br J Radiol 2012;85:1566-1575.

10 McKinney AM, Short J, Truwit CL, McKinney ZJ, Kozak OS, SantaCruz KS, Teksam M: Posterior reversible encephalopathy syndrome: incidence of atypical regions of involvement and imaging findings. AJR Am J Roentgenol 2007;189:904-912. 
Wardrope et al.: Acute Respiratory Distress Syndrome and Posterior Reversible Encephalopathy Syndrome following Rituximab Therapy

11 Li Y, Jenny D, Castaldo J: Posterior reversible encephalopathy syndrome: clinicoradiological spectrum and therapeutic strategies. Hosp Pract (1995) 2012;40:202-213.

12 Lamy C, Oppenheim C, Mas JL: Posterior reversible encephalopathy syndrome. Handb Clin Neurol 2014;121:1687-1701.

13 Bartynski WS: Posterior reversible encephalopathy syndrome, part 2: controversies surrounding pathophysiology of vasogenic edema. AJNR Am J Neuroradiol 2008;29:1043-1049.

14 Palma J-A, Gomez-Ibañez A, Martin B, Urrestarazu E, Gil-Bazo I, Pastor MA: Nonconvulsive status epilepticus related to posterior reversible leukoencephalopathy syndrome induced by cetuximab. Neurologist 2011;17:273-275.

$\checkmark 15$ Jayaweera JL, Withana MR, Dalpatadu CK, Beligaswatta CD, Rajapakse T, Jayasinghe S, Chang T: Cyclophosphamide-induced posterior reversible encephalopathy syndrome (PRES): a case report. J Med Case Rep 2014;8:442.

16 Wu Q, Marescaux C, Wolff V, Jeung M-Y, Kessler R, Lauer V, Chen Y: Tacrolimus-associated posterior reversible encephalopathy syndrome after solid organ transplantation. Eur Neurol 2010;64:169-177.

17 Mizutani M, Nakamori Y, Sakaguchi H, Kageyama Y, Oya E, Ino K, Suzuki K, Sekine T: Development of syndrome of inappropriate secretion of $\mathrm{ADH}$ and reversible posterior leukoencephalopathy during initial rituximab-CHOP therapy in a patient with diffuse large B-cell lymphoma (in Japanese). Rinsho Ketsueki 2013;54:269-272.

-18 Hosoi M, Yamamoto G, Imai Y, Kurokawa M: Reversible posterior leukoencephalopathy syndrome following R-CHOP therapy for diffuse large B-cell lymphoma. Ann Hematol 2010;89:207-208.

-19 Haefner MD, Siciliano RD, Widmer LA, Vogel Wigger BM, Frick S: Reversible posterior leukoencephalopathy syndrome after treatment of diffuse large B-cell lymphoma. Onkologie 2007;30:138-140.

-20 Sánchez-Carteyron A, Alarcia R, Ara JR, Martín J: Posterior reversible encephalopathy syndrome after rituximab infusion in neuromyelitis optica. Neurology 2010;74:1471-1473.

-21 Hadjinicolaou AV, Nisar MK, Parfrey H, Chilvers ER, Ostör AJK: Non-infectious pulmonary toxicity of rituximab: a systematic review. Rheumatology (Oxford) 2012;51:653-662.

-22 Saito B, Nakamaki T, Adachi D, Suzuki J, Tomoyasu S: Acute respiratory distress syndrome during the third infusion of rituximab in a patient with follicular lymphoma. Int J Hematol 2004;80:164-167.

23 Chan KH, Ng MKC: Hyperacute pulmonary edema complicating rituximab infusion. Eur J Intern Med 2009;20:e13.

-24 Smith MR: Rituximab (monoclonal anti-CD20 antibody): mechanisms of action and resistance. Oncogene 2003;22:7359-7368.

25 Bienvenu J, Chvetzoff R, Salles G, Balter C, Tilly H, Herbrecht R, Morel P, Lederlin P, Solal-Celigny P, Audhuy B, Christian B, Gabarre J, Casasnovas O, Marit G, Sebban C, Coiffier B: Tumor necrosis factor alpha release is a major biological event associated with rituximab treatment. Hematol J 2001;2:378-384.

-26 Martínez-Martínez MU, Abud-Mendoza C: Recurrent diffuse alveolar haemorrhage in a patient with systemic lupus erythematosus: long-term benefit of rituximab. Lupus 2012;21:1124-1127.

27 Lin C-Y, Chen H-C, Hwang W-L, Teng C-L: Immune thrombocytopenic pupura-induced reversible posterior leukoencephalopathy successfully treated by rituximab. Ann Hematol 2011;90:731-732.

28 Chvojka J, Krouzecký A, Radej J, Sýkora R, Karvunidis T, Novák I, Matejovic M: 24-year-old male with fever, multi-organ dysfunction and fast progressing ARDS (in Czech). Vnitr Lek 2009;55:991-994. 
Case Reports in

Nephrology

and Dialysis
Case Rep Nephrol Dial 2016;6:32-39

Wardrope et al.: Acute Respiratory Distress Syndrome and Posterior Reversible Encephalopathy Syndrome following Rituximab Therapy

Table 1. Initial blood results and vasculitic screen

\begin{tabular}{|c|c|c|}
\hline Test & Result & Normal range \\
\hline White blood cells, $\times 10^{9} / 1$ & 7.8 & $4-10$ \\
\hline Haemoglobin, g/l & 102 & $120-150$ \\
\hline Platelets, $\times 10^{9} / 1$ & 279 & $150-400$ \\
\hline Sodium, mmol/l & 131 & $135-145$ \\
\hline Potassium, mmol/l & 3.8 & $3.5-5$ \\
\hline Urea, mmol/l & 13.6 & $2.5-7.8$ \\
\hline Creatinine, $\mu \mathrm{mol} / \mathrm{l}$ & 167 & $49-90$ \\
\hline Albumin, g/l & 28 & $35-50$ \\
\hline Liver function tests & normal & variable \\
\hline Prothrombin time, $\mathrm{s}$ & 11 & $11-14$ \\
\hline Fibrinogen, g/l & 4.2 & $1.8-4$ \\
\hline Serum electrophoresis & normal & \\
\hline Immunofixation & IgMk paraprotein & \\
\hline ANA & $1 / 640$ speckled & $<1 / 40$ \\
\hline Anti-CCP, U/ml & 0.7 & $0-4.8$ \\
\hline $\mathrm{CH} 50, \mathrm{U} / \mathrm{ml}$ & $<15.9$ & $31-50$ \\
\hline ANCA (MPO/PR3) & negative & \\
\hline $\mathrm{C} 3, \mathrm{~g} / \mathrm{l}$ & 0.98 & $0.75-1.65$ \\
\hline $\mathrm{C} 4, \mathrm{~g} / \mathrm{l}$ & 0.01 & $0.20-0.65$ \\
\hline Anti-DsDNA, IU/ml & 9.9 & $<10$ \\
\hline ENA & negative & \\
\hline HEP B, C, HIV & negative & \\
\hline Aspergillus prec. & negative & \\
\hline CD5, CD19, CD20, CD45 & normal & \\
\hline C1E inhibitor & normal & \\
\hline
\end{tabular}

Table 2. All reported cases of PRES following rituximab to date

\begin{tabular}{lllllll}
\hline Case & Disease & Onset & Outcome & Reintroduced & $\begin{array}{l}\text { Time to } \\
\text { recovery }\end{array}$ & Risk factors \\
\hline 1 & & & & & 1 week & HTN \\
2 & Cryoglobulinaemia & $24 \mathrm{~h}^{\mathrm{a}}$ & Recovery & No & $24 \mathrm{~h}$ & Cyclophos \\
3 & B-cell lymphoma & 4 days & Recovery & No & $40 \mathrm{~h}$ & Cyclophos \\
4 & B-cell lymphoma & Immediate & Recovery & Yes $(\times 7)$ & $2-3$ days & Cyclophos \\
5 & Neuromyelitis & $2-21$ days & Recovery & Yes & 8 days & \\
6 & SLE & $8 \mathrm{hc}^{\mathrm{c}}$ & Recovery & No & $24 \mathrm{~h}$ & SLE, HTN \\
7 & Hepatitis C & 'recent' & Recovery & Yes & 1 week & \\
\hline
\end{tabular}

HTN = Hypertension; Cyclophos $=$ cyclophosphamide; SLE = systemic lupus erythematosus. ${ }^{\text {a }}$ After the second dose, 1 st dose one week prior. b 21 days after 1 st dose, 2 days after 2 nd. c received 3 infusions, PRES symptoms developed within $8 \mathrm{~h}$ of each. 


\section{Case Reports in \\ Nephrology \\ and Dialysis}

\begin{tabular}{l|l}
\hline Case Rep Nephrol Dial 2016;6:32-39 \\
\hline DOI: $10.1159 / 000444250$ & $\begin{array}{l}\text { (c) 2016 The Author(s). Published by S. Karger AG, Basel } \\
\text { www.karger.com/cnd }\end{array}$ \\
\hline
\end{tabular}

Wardrope et al.: Acute Respiratory Distress Syndrome and Posterior Reversible Encephalopathy Syndrome following Rituximab Therapy

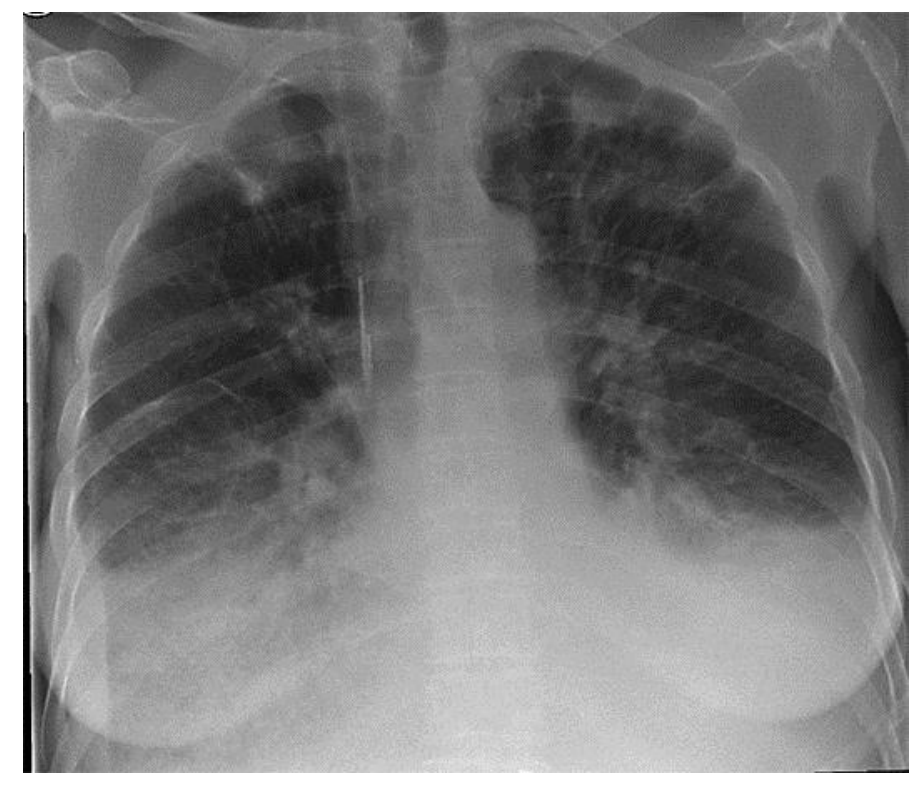

Fig. 1. Acute pulmonary oedema following rituximab treatment.

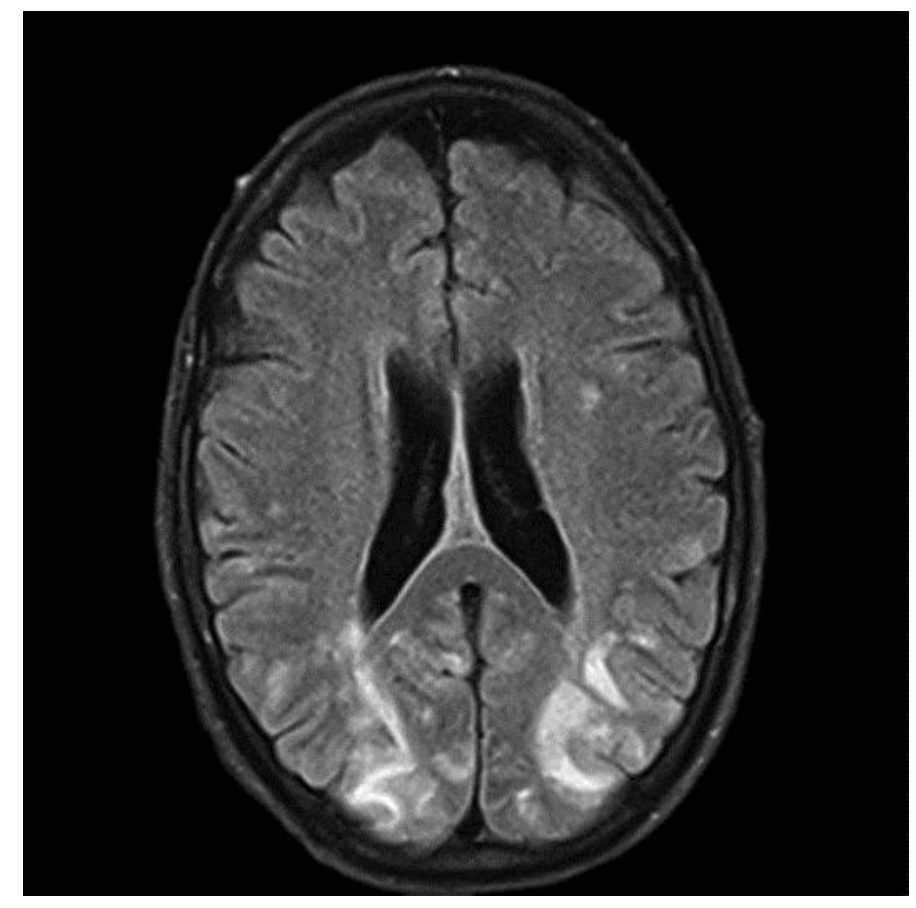

Fig. 2. MRI of the brain showing high T2 and FLAIR signal in the occipital and posterior parietal subcortical white matter consistent with PRES following treatment with rituximab. 